\title{
Musulmanes y Política: Las comunidades islámicas como grupos de interés religioso
}

\section{Muslims and Politics: Islamic communities as religious interest groups}

\author{
Iván MEDINA \\ Universidad Autónoma de Madrid \\ ivan.medina@uam.es \\ José Antonio PeÑa-Ramos \\ Universidad Pablo de Olavide, de Sevilla \\ japer@ugr.es
}

Recibido: 16.12 .2010

Aprobado definitivamente: 21.12 .2012

\section{RESUMEN}

La creciente presencia de musulmanes en España configura nuevas reivindicaciones y tensiones que examinan la capacidad de la sociedad española para aceptar "otras" religiones y "otras" prácticas culturales. Partiendo de una noción de grupos de interés, cabe esperar la creación de asociaciones que representen dichos intereses. Este trabajo analiza el comportamiento colectivo y la configuración de intereses de los musulmanes a nivel local, en la ciudad de Granada. Partimos de dos estudios de caso para trazar nuestras conclusiones: por un lado, la larga reivindicación musulmana de disponer de un cementerio islámico y, por otro, la tensa negociación en torno a la celebración del Día de la Toma. Se ha empleado una metodología cualitativa basada en entrevistas a los actores principales así como referencias a prensa local, documentos oficiales e informes privados. Se exponen varias conclusiones: primero, en referencia a su organización, debemos entender a las comunidades islámicas, variadas, numerosas y no siempre conectadas, como los principales referentes asociativos. Segundo, su influencia vendrá caracterizada por su (hasta la fecha) situación de outsiders, aspecto que les impedirá desarrollar estrategias de alto impacto a corto plazo. Y, tercero, la persistencia en sus tareas de presión les lleva a lograr, de forma completa o parcial, sus objetivos.

Palabras Clave: Musulmanes, comunidades islámicas, grupos de interés religioso, Islam, Granada.

\begin{abstract}
The growing presence of Muslims in Spain sets new demands and strains that examine the ability of Spanish society to accept "other" religions and "other" cultural practices. Based on a concept of interest groups, we can expect the creation of associations representing those interests. This paper analyzes the collective behaviour and configuration of interests of Muslims in the city of Granada. We rely on two case studies to draw our conclusions: first, the long Muslim claim to have an Islamic cemetery and, secondly, the tense negotiations about "el Día de la Toma". We have used a qualitative methodology based on interviews with key players and references to local press, official documents and private reports. We provide some conclusions: first, in regard to their organization, we must understand the Islamic communities -varied, numerous and not always connected- as the most representative interlocutors. Second, their influence will be characterized by their (to date) outsider position, something that will prevent them from developing high-impact, short-time strategies. And third, continuity in claims leads them to achieve, in whole or in part, their goals.
\end{abstract}


KEYwORDs: Muslims, Islamic communities, religious interest groups, Islam, Grenada.

\section{SUMARIO}

1.Introducción. 2.Las comunidades islámicas como grupos de interés religioso. 3.La capacidad de influencia de las comunidades islámicas: algunas hipótesis de partida. 4.Estudios de caso. 5.Apuntes finales sobre las características y dinámicas entre los actores 


\section{INTRODUCCIÓN}

Escasos son los estudios sobre grupos de interés religioso en la joven ciencia política española. En nuestro país, al margen de considerar (históricamente) influyente a la Iglesia Católica (Linz, 1987; Mella, 1989), la "actividad de presión [de otras confesiones religiosas] casi no ha trascendido ante la opinión pública y se ha limitado a una estrategia negociadora para conseguir un primer reconocimiento público de su presencia en España" (Molins y Casademunt, 2001: 489). Las repetidas concesiones que el régimen democrático ha ofrecido a la Iglesia Católica -sirva de ejemplo particular la mención especial que de ella se hace en la Constitución de 1978- ayuda a percibir una cierta necesidad por institucionalizar los asuntos religiosos $\mathrm{y}$, por ende, a aliviar posibles tensiones entre el Estado y la Iglesia. Esta solución corporativa se ha ido considerando a lo largo de las últimas décadas como el encaje idóneo para unos intereses apaciguados ante la pujante secularización de la sociedad (Pérez-Ágote, 2007; Taylor, 2007).

$\mathrm{Si}$ es este un sistema corporativo, es decir, si se reconoce públicamente la representatividad de una confesión mayoritaria, ¿por qué fijarnos en aquellas religiones que el propio Estado ha considerado minoritarias? ${ }^{1}$ Digamos que, por un lado, por una necesidad de explicar un nuevo escenario político generado por una realidad social cambiante y, por otro lado, a consecuencia de ello, para dar cuenta del incipiente mapa de actores y de sus prácticas, aunque sea todavía descrito a partir de pequeñas experiencias. Entre los cambios a los que se hace referencia, dos a destacar: por un lado, la complicada adaptación social y política a una repentina inmigración, marcada por sucesivas leyes reguladoras de los flujos migratorios, políticas públicas de integración carentes de un liderazgo institucional coordinado y la aparición de tensiones raciales y xenófobas (Ruiz, 2003; Zapata-Barrero, 2003). Por otro lado, la revitalización de la cultura y la religión en el debate político que, indudablemente, ha regenerado el frame con el que se hace frente a la integración de inmigrantes y el diálogo interreligioso (Maussen,
2006). Por consiguiente, si aceptamos la existencia de nuevas tensiones y reclamaciones de perfil religioso (Kackett, 2005), entonces debemos considerar la existencia de un interés latente, expectante a una favorable estructura de oportunidad política para emerger como grupo de interés, tal y como perfiló David Truman (1951) décadas atrás.

Lo que pretende este trabajo es analizar la acción colectiva de los musulmanes en España tomando como referencia el mundo local, pues es allí donde su actividad política es más activa. Dejaremos muestras de la capacidad de influencia de las comunidades islámicas y de las estrategias de presión que han seguido tomando como ejemplo dos experiencias políticas en el municipio de Granada. Estos dos casos de estudio son, primero, lo referente a la adaptación y concesión de una parcela dentro del Cementerio municipal granadino para llevar a cabo enterramientos bajo el rito islámico $\mathrm{y}$, segundo, el proceso relacionado con la celebración del Día de la Toma. Nos interesa descifrar, especialmente, su forma organizativa, el acceso a los recursos, la selección de estrategias y las barreras fijadas por el contexto institucional.

Se ha empleado una metodología cualitativa para elaborar este trabajo. Para detallar el desarrollo histórico de las dos políticas ha sido necesario recurrir a la prensa local granadina, a documentos institucionales (más o menos accesibles), a informes de particulares y a una selección de publicaciones sobre la estela musulmana en la ciudad. Estas técnicas han sido completadas mediante la realización de entrevistas a los actores más destacados en cada uno de los casos de estudio. De todas ellas, dieciséis entrevistas se han planteado a líderes -o personas sugeridas por ellos- de las comunidades islámicas en Granada, ocho entrevistas han recogido la opinión de actores institucionales, seleccionados previamente a partir de su relevancia en el desarrollo de la política, y, finalmente, se han realizado cuatro entrevistas a expertos.

\footnotetext{
${ }^{1}$ El concepto de "notorio arraigo" es novedoso en el ordenamiento jurídico español. Su ambigüedad implica que cada solicitud de reconocimiento del notorio arraigo por parte de una confesión tenga que ser examinada específicamente por la Comisión Asesora de Libertad Religiosa. Véase, en este sentido, Rodríguez Ramos (2009).
} 


\section{LAS COMUNIDADES ISLÁMICAS COMO GRUPOS DE INTERÉS RELIGIOSO}

Gregorian (2003) se ha referido gráficamente a la idiosincrasia del Islam como un mosaico y no como un monolito. Cuatro son las denominaciones que conforman el Islam: sunísmo, chiísmo, jariyismo y sufismos. ${ }^{2}$ A estas diferencias por razón religiosa debemos sumarle aquellas derivadas del origen de los fieles. El Islam acoge a más de 1.200 millones de personas y se extiende por Asia, África, América y Europa. Dispares realidades sociopolíticas y económicas y legados históricos les caracterizan. Así, Warner y Wenner (2006) han ofrecido una clara cita sobre la estructura religiosa, social y política del Islam:

"Islam is a decentralized, non-hierarchical religion with multiple and often competing schools of law and social requirements. [...] In contrast to Catholicism, Islamic religious leaders have no enforcement mechanisms to obtain obedience from their adherents; there are no sacraments in Islam which can be withheld from Muslims in order to obtain compliance with the wishes of imams or other 'clerics' regarding policy decisions which they may support or condone. [...] Islam's decentralized structure prevents Islamic organizations from making credible commitments about their actions to others. Further, Islam does not provide organizational structure which can easily give private rewards to those who participate in collective action and which can punish those who free-ride. This lack of hierarchical religious authority is exacerbated in Europe, where there is no embedded Islamic tradition or state support for a particular religious interpretation and set of practices".

(Warner y Wenner, 2006: 461)

A la luz de estos rasgos de organización religiosa, en España, en general, y en Granada, en particular, los musulmanes han tenido grandes dificultades para establecer grupos representativos y unitarios, bien en federaciones o partidos políticos (ver PeñaRamos y Medina, 2011; Peña-Ramos, 2012). A nivel estatal, dos asociaciones representan a los musulmanes: la Federación Española de Entidades Religiosas (FEERI), surgida en 1989, y la Unión de Comunidades Islámicas de España (UCIDE), creada en 1991 a partir de la escindida Asociación Musulmana de España (AME). Ambas se federaron en la Comisión Islámica de España (CIE), en 1992, ante la exigencia del Estado, pero sus desencuentros han sido constantes. Por otro lado, escasos partidos políticos de base musulmana habitan las instituciones españolas con la salvedad de las ciudades autónomas de Ceuta y Melilla. En Granada, en febrero de 2009, se gestó un prototipo de partido político bajo la denominación Partido Renacimiento y Unión de España (PRUNE), cuyo rechazo por parte de algunos colectivos musulmanes fue notable (Peña-Ramos, 2009). Cabría margen de discusión para sugerir que el contexto político e institucional son un obstáculo insalvable (Goldberg, 2006). Podría serlo, como en alguna ocasión han manifestado sus promotores, el burocrático proceso de inscripción en el Registro de Entidades Religiosas del Ministerio de Justicia. ${ }^{3}$ Sin embargo, no debería obviarse los impedimentos generados en base a los factores organizativos.

La ausencia de referentes "cúpula" obliga a los musulmanes a articular comunidades locales que sirvan como espacios hegemónicos de referencia para prestar asistencia religiosa, ser un punto de reunión cultural y definir una propia identificación social (Moreras, 1999). Estas son, al mismo tiempo, el primer espacio de mediación entre los musulmanes y las autoridades locales (Rath et. al., 2001). Es por ello que los colectivos musulmanes, especialmente a través de sus mezquitas, asociaciones, centros y plataformas, acaban convirtiéndose en grupos de interés (Klausen, 2005; Tarrés, 2005; Buades y Vidal, 2007). Mientras que el nivel estatal se convierte en la sala donde se discuten los marcos jurídicos, a nivel local tienen lugar las negociaciones para instalar una mezquita, adaptar el cementerio islámico, regenerar los barrios musulmanes, escolarizar a los niños recién llegados, gestionar las licencias de establecimientos a los musulmanes, etc.

\footnotetext{
${ }^{2}$ Estas son ramas que comparten las mismas creencias religiosas pero con importantes diferencias jurídicas, sociales y teológicas.

${ }^{3}$ Se puede acceder al registro de forma virtual en la siguiente dirección web: http://dgraj.mju.es/EntidadesReligiosas/ < consultado el 2 de Septiembre de 2010>.
} 
Estas comunidades, que promueven la religión como una fuente alternativa a la identidad social y nacional, a menudo reciben sustento de países islámicos u organizaciones de la Diáspora (Pfaff y Gill, 2006). Estas conexiones extranjeras pueden entenderse como una causa de la fragmentación política entre ellas pues les obligan a seguir ciertos dictados acordes con una denominación. Tampoco parece que necesiten de la colaboración de recursos al tener garantizada su supervivencia y provisión básica. Es también fuente de distorsión la posibilidad de que los líderes de las mezquitas no deban ser sacerdotes. En la medida en que el líder pueda actuar como un emprendedor, agrupando seguidores en torno a una causa religiosa e identitaria, se puede estar facilitando la búsqueda de beneficios individuales en boca de intereses colectivos en las negociaciones con las autoridades (ver Salisbury, 1969).

La falta de una doctrina consensuada permite la existencia de varias mezquitas en el mismo municipio y, especialmente, la voluntad de los musulmanes de mantener esta distinción. Cada una de esas mezquitas forjará un mensaje sobre cómo entender el mundo y cómo deben sus fieles actuar, desde posiciones moderadas a otras más extremistas. Por su parte, el Estado, en su propósito regulador, se enfrenta -persiguiendo o ilegalizando- a aquellas comunidades cuyos actos y discursos no sean tolerados política y socialmente. Por consiguiente, la adhesión de los musulmanes a ellas no se debe exclusivamente a una cuestión de autoidentificación (religiosa, nacional, social). Se debe tener en cuenta una concepción más amplia de la política interna de la comunidad religiosa definida por cuatro factores: a) la doctrina religiosa, b) los objetivos que persigue, c) los medios para hacer cumplir dichos objetivos así como d) los beneficios e incentivos que se ofrecen (Marczewska-Rytko, 2003).

Haciendo referencia al caso granadino, la mayoría de los musulmanes asentados en el municipio de Granada (que en 2007 contaba con unos 7.000 habitantes $)^{4}$, independientemente de su afiliación o pertenencia a otro tipo de organizaciones con mayor o menor significación confesional, pertenecen a alguna de las cinco comunidades islámicas locales. Se pueden observar en la Tabla 1 algunas diferencias significativas entre ellas. Su trayectoria, número de fieles y relación con otros actores es variable; incluso una de ellas no se encuentra inscrita en el RER ${ }^{5}$. Sin embargo, cada una está vinculada a una de las cinco mezquitas existentes en el municipio de Granada.

\begin{tabular}{|c|c|c|c|c|c|c|}
\hline Nombre & $\begin{array}{c}\text { Fecha de } \\
\text { inscripción* } \\
\text { (orden creciente) }\end{array}$ & Sección** & $\begin{array}{l}\text { Tamaño } \\
\text { estimado } \\
\text { (n. } .^{\circ} \text { de } \\
\text { fieles) }\end{array}$ & Líder & Mezquita & $\begin{array}{c}\text { Relación } \\
\text { con otros } \\
\text { actores }\end{array}$ \\
\hline $\begin{array}{l}\text { Comunidad Islámica } \\
\text { en España }\end{array}$ & 19/09/1980 & Especial & 120 & $\begin{array}{l}\text { Ahmed Ber- } \\
\text { mejo }\end{array}$ & $\begin{array}{l}\text { Mezquita } \\
\text { Mayor de } \\
\text { Granada }\end{array}$ & Baja \\
\hline $\begin{array}{l}\text { Comunidad Musulma- } \\
\text { na de Granada }\end{array}$ & 26/03/1990 & Especial & 150 & $\begin{array}{c}\text { Lahsen el } \\
\text { Himer }\end{array}$ & $\begin{array}{l}\text { Mezquita } \\
\text { Omar }\end{array}$ & Alta \\
\hline $\begin{array}{l}\text { Comunidad Musul- } \\
\text { mana Española de la } \\
\text { Mezquita del Temor } \\
\text { Allah en Granada }\end{array}$ & 01/03/1996 & Especial & 350 & $\begin{array}{c}\text { Zakaría Maza } \\
\text { Vielva }\end{array}$ & $\begin{array}{l}\text { Mezquita } \\
\text { At-Taqwa }\end{array}$ & Alta \\
\hline $\begin{array}{l}\text { Mezquita de la Paz } \\
\text { "As-Salam" }\end{array}$ & 25/10/1999 & Especial & 400 & $\begin{array}{l}\text { Abdul-Qader } \\
\text { AbuHusni }\end{array}$ & $\begin{array}{l}\text { Mezquita } \\
\text { de la Paz } \\
\text { (Assalam) } \\
\end{array}$ & Alta \\
\hline $\begin{array}{l}\text { Asociación Masalical } \\
\text { Jinan }\end{array}$ & $\begin{array}{l}\text { (Pdte. de registro } \\
\text { como entidad } \\
\text { religiosa) }\end{array}$ & -- & 200 & $\begin{array}{l}\text { Serigne Cheikh } \\
\text { Diop }\end{array}$ & $\begin{array}{l}\text { Masalical } \\
\text { Jinan }\end{array}$ & Baja \\
\hline
\end{tabular}

Fuente: Elaboración propia a partir de entrevistas y de datos del Ministerio de Justicia [en línea]

* Fecha de inscripción en el RER.

** En la Sección Especial se inscriben: las Iglesias, Confesiones y Comunidades que hayan firmado el Acuerdo de cooperación con el Estado y las entidades religiosas de naturaleza asociativa creadas por ellas mismas; y las entidades de naturaleza asociativa erigidas canónicamente por la competente autoridad de la Iglesia Católica. 


\section{LA CAPACIDAD DE INFLUENCIA DE LAS COMUNIDADES ISLÁMICAS: ALGUNAS HIPÓTESIS DE PARTIDA}

Son caras de una misma moneda conocer, por un lado, quién forma parte de un grupo y, por otro lado, qué estrategias y resultados (tangibles o intangibles) han logrado (Bentley, 1908). Para ser considerados como un grupo de interés, una asociación, un club, una organización o una comunidad deben tener una intención política, es decir, en algún momento deben haber mostrado su vocación de influir en la definición de la agenda, en la toma de decisiones o en la creación de las políticas (Knoke, 1986; Heinz et al.; 1993). De hecho, el estudio de los grupos de interés ha estado tradicionalmente dirigido a valorar quién consigue qué, cuándo y cómo (Cerny, 2006).

A pesar de que la literatura sobre grupos de interés ha sido producida, en gran medida, teóricamente polarizada, conceptualmente inconexa y empíricamente intermitente (Baumgartner y Leech, 1998), ${ }^{6}$ se ha llegado a un mínimo consenso respecto a que la tarea de presión es un algo así como un indetermi- nado puzzle entre la organización interna del grupo, la configuración de las demandas, las características del proceso político y la estructura institucional (Knoke, 1990). El dilema de la acción colectiva obedece a la voluntad de unos individuos de crear (y mantener) un grupo capaz de decidir estratégicamente la forma justa y el momento preciso para hacer que el gobierno haga suyas sus prioridades. Una serie de proposiciones instan a valorar que el grupo más cohesionado, visible, representativo, experimentado, creíble, heterogéneo, eficaz y legitimado acaba siendo el más influyente (Chamberlin, 1974; Salisbury, 1984; Udhen, 1993). Razón de ello es su capacidad para acceder a los núcleos de decisión y desarrollar tácticas formales mucho más influyentes que, por ejemplo, manifestaciones esporádicas o reparto de panfletos (Berry, 1977; Maloney et al., 1994). Claro está, además, que en este proceso intervienen un gran conjunto de variables (indeterminadas) que inciden directa e indirectamente en la actividad política de los grupos y cómo éstos se relacionan entre sí.

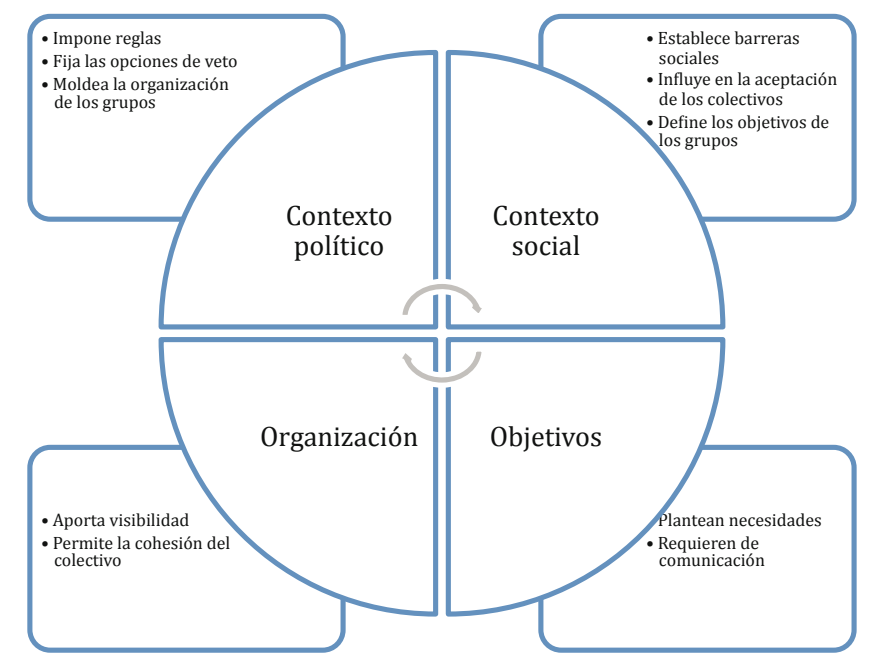

${ }^{4}$ Esta cifra nos fue proporcionada, durante la realización de nuestro trabajo de campo, por la Asociación de Mediadores Interculturales (ASMIN) de Granada, la cual infirió a partir de la información del Padrón Municipal de Habitantes, de los datos facilitados por las comunidades islámicas del municipio y por determinadas ONG, y de estimaciones propias.

${ }^{5}$ La Asociación Masalical Jinan se encontraba pendiente de tramitar su inscripción en el RER en el momento de concluir este estudio.

${ }^{6} \mathrm{Al}$ no ser objetivo de este trabajo hacer una revisión exhaustiva de la literatura sobre grupos de interés, baste con mencionar que las escuelas a las que nos referimos aquí son: el pluralismo, el neocorporatismo, el elitismo y las redes de políticas. Pueden encontrarse excelentes trabajos y manuales que presentan sus principales características y puntos de conflicto. Sugerimos la lectura de Dunleavy y O’Leary (1987) y Knoke (1994). 
Para el caso que nos ocupa, de forma breve, como se expuso en el punto anterior, ni el contexto ni la forma organizativa de las comunidades islámicas parecen indicar que los musulmanes sean capaces de alcanzar, a corto plazo al menos, cambios en la percepción de los españoles ${ }^{7}$ ni tampoco desplegar políticamente una gran ofensiva de presión. El marco de interpretación que enmarca los asuntos religiosos sigue siendo bastante pernicioso y resulta complicado separar del debate sobre la integración las referencias a la seguridad y el fanatismo religioso (Stenger, 2005). Repetidas referencias a la Islamofobia, la criminalización de las políticas de integración o la incrustada marginalización de los inmigrantes son comunes entre los especialistas (Labrador, 2004; Zapata-Barrero, 2006, 2010). Esta argumentación -debatida por la opinión pública, la opinión publicada y los foros académicos- tiene su consecuencia práctica en el establecimiento de barreras sociales (informales y formales) (Bail, 2008), es decir, en la construcción ciudadana de un sentimiento de pertenencia reflejado en símbolos -ropa, espacios, instituciones, edificios- que son, a su vez, los principales elementos de identidad cultural de cualquier inmigrante. Además, los musulmanes no han dado muestras de una poderosa capacidad de articulación colectiva de sus intereses. Al no disponer de un referente político o social visible que dialogue con el gobierno y el resto de confesiones religiosas, sus demandas han sido en gran medida desconocidas más allá de las reivindicaciones locales.

De todas formas, si el ejercicio de la influencia acaba siendo una cuestión referente a cómo " $A$ logra convencer a $B$ para que haga lo que de otro modo no haría" (Dahl, 1957), bien sea amparándose en el control de las instituciones o en la manipulación de los recursos, ${ }^{8}$ una vez clasificados los elementos que definen dicho ejercicio, una opción bastante acertada para valorar la influencia real de un grupo es recurrir a su efectividad, es decir, a la capacidad de un grupo para ver realizadas sus reivindicacio- nes (Grant, 1989: 113). Obvio es que este método requiere de una perspectiva histórica que permita observar la evolución de la política, describir a los actores, analizar la mutación de sus demandas y discriminar entre vencedores y vencidos. Lo que sería un inconveniente en algunos casos, la aplicación de este método en este trabajo resulta útil para testar alguna de nuestras hipótesis referidas a la temporalidad con la que se piensan las estrategias de presión. De tal modo, cuatro hipótesis se proponen sobre la efectividad de las comunidades islámicas:

1. Hipótesis 1 (H1): la efectividad de una comunidad islámica está altamente impedida por el contexto político y social.

2. Hipótesis 2 (H2): las autoridades locales evitarán llegar a compromisos formales con las comunidades islámicas dada la controversia religiosa y cultural de sus peticiones.

3. Hipótesis 3 (H3): la fragmentación entre comunidades islámicas impedirá desarrollar estrategias y liderazgos a corto plazo y unitarias.

4. Hipótesis $4(\mathrm{H} 4)$ : las comunidades islámicas persistirán en su tarea de presión si sus objetivos están relacionados con su identidad cultural y religiosa.

A continuación se expone la experiencia de las comunidades islámicas granadinas en la defensa de sus reclamaciones de disponer de un cementerio islámico en el municipio y de modificar la celebración del Día de la Toma. Para cada caso, se realiza una descripción de los principales sucesos, destacando los intereses de las comunidades islámicas, su interacción con otros actores implicados en la toma de decisión y las tácticas empleadas. Además, se presenta una descripción de los actores de acuerdo a su tipología, objetivos, presencia en el proceso político y nivel de comunicación con otros actores.

\footnotetext{
${ }^{7}$ La edición impresa de EL PAÍS del 9 de septiembre del 2010, página 30, se hacía eco de una encuesta sobre antisemitismo elaborada por la Casa Sefarad Israel. El titular era el siguiente: "Un tercio de los españoles tiene una mala opinión de los judíos. Un 35\% admite su rechazo al pueblo hebreo y un 53\%, a los musulmanes".

${ }^{8}$ Estos matices responden a la discusión teórica del concepto "poder" y cómo un actor puede ejercerlo intencionadamente sobre otro mediante impedimento (Bachrach y Baratz, 1962), manipulación (Lukes, 1974) o construcción ideológica de lo aceptado (Digesser, 1992).
} 


\section{ESTUDIOS DE CASO}

\subsection{El Cementerio islámico: treinta años de reivindicaciones e incumplimientos}

El cementerio islámico de Granada está acotado en el cementerio municipal, en la finca de la Dehesa del Generalife, que forma parte del conjunto del Generalife. ${ }^{9}$ En 1921 el Estado recuperó la propiedad de la parcela, mientras que el Ayuntamiento se ocuparía de su gestión desde que el alcalde lo aprobara en $1938 .{ }^{10} \mathrm{Al}$ acabar la dictadura franquista, a la par que se promulgaba la ley sobre "entierros municipales" (Ley 49/1978), que obliga de realizar entierros sin discriminación alguna, el primer Estatuto de Autonomía de Andalucía (1981, artículo 13.27) garantizaba la competencia exclusiva autonómica en materia de patrimonio, haciendo a la región competente de la decisión sobre el uso de la finca. A su vez, se creaba el Patronato de la Alhambra y El Generalife, un organismo público entre las administraciones central y andaluza, que sería el encargado de preservar y gestionar ambos Patrimonios Mundiales de la UNESCO (Soddu, 2003).

La realización de entierros bajo el rito islámico en este cementerio se reanudó en 1980 por la primera comunidad musulmana establecida en Granada, la Sociedad para el Retorno al Islam en España. Las peticiones iniciales se centraban en la regularización de los entierros y la dignificación del cementerio islámico, que debería comenzar por vallar su perímetro. Tales demandas toparon con la postura del Ayuntamiento que ya en 1982 se negó a construir la cerca, a pesar de que las comunidades musulmanas habían propuesto cubrir los costes mediante las prestaciones de algunos Estados árabes. ${ }^{11}$ Ante la negativa, las comunidades musulmanas en el municipio comenzaron a reclamar, acorde con un cambio de estrategia, la firma de un acuerdo de colaboración con el gobierno local. En 1983, después de las repetidas peticiones de las comunidades musulmanas, la secretaría general del Ayuntamiento reconoció la transferencia en el uso de ese patrimonio a las comunidades musulmanas, instando a vallar el cementerio y proseguir con los entierros (Soddu, 2003).

No hubo mayores problemas hasta 1993, año en el que los administradores del cementerio municipal se negaron a trasladar a un musulmán fallecido al cementerio islámico. Los gerentes, con el apoyo gubernamental, justificaron su decisión basada en cuestiones jurídicas. Se prohibieron nuevos enterramientos islámicos en el cementerio, argumentando que el carácter aconfesional del cementerio municipal permitía acoger todo tipo de entierros. La situación, rechazada por las tres comunidades islámicas existentes en aquel momento en la ciudad, generó un alto grado de tensión entre musulmanes y autoridades municipales. Las comunidades expresaron su total desacuerdo con esta decisión y pidieron a las autoridades municipales soluciones más favorables a sus intereses, especialmente, alguna de las siguientes alternativas: o bien continuar con los entierros en el cementerio islámico (opción preferida) o bien destinar una parcela dentro del cementerio municipal para entierros musulmanes. Bajo ningún concepto, las comunidades estaban dispuestas a aceptar que los próximos fallecidos no fueran enterrados en cementerio islámico.

Varios meses después el hijo recién nacido de un matrimonio musulmán fallecía. En vista de la situación, el padre del niño convocó inesperadamente frente a los juzgados a unos cincuenta musulmanes. Los manifestantes, que portaban un ejemplar de la Constitución española en una mano y el Corán en la otra, protestaron enérgicamente por la situación, que entendían como indefensión, aprovechando la presencia de los medios de comunicación (televisión y prensa), que habían sido convocados con anterioridad por parte de las comunidades. Ante tal escenario, el juez se prestó a recibir a los manifestantes y decidió permitir que el entierro tuviera lugar en el cementerio islámico, al que asistieron la mayoría de musulmanes de Granada. Según la opinión de las comunidades islámicas, el episodio no hacía más que mostrar la necesidad de acelerar la firma de un

\footnotetext{
${ }^{9}$ Palacio destinado por los reyes musulmanes a lugar de descanso construido en los siglos XII-XIV.

${ }^{10} \mathrm{El}$ primer uso del cementerio islámico fue como cementerio de guerra para permitir el enterramiento de los soldados de la Guardia Mora de Franco durante la Guerra Civil española (1936-1939).

${ }^{11}$. De hecho, los entierros se eran sufragados en su totalidad por las propias comunidades.
} 
acuerdo con el Ayuntamiento para permitir los entierros y ceder la gestión del cementerio islámico.

El cumplimiento de la Ley 26/1992, por la que se constituyó el Acuerdo de Cooperación entre el Estado y la Comisión Islámica de España (CIE), era la principal fuente de legitimidad en la que se apoyaban las comunidades. En su artículo 2.5 se reconocía a las comunidades islámicas que pertenecieran a la CIE: a) el derecho a que se reserven parcelas para enterramientos musulmanes en los cementerios municipales, b) el derecho a poder gestionar sus propios cementerios islámicos $\mathrm{y}, \mathrm{c}$ ) el derecho a realizar funerales de acuerdo con las normas islámicas. En ese sentido, en 1994 el Patronato de la Alhambra y el Generalife confirmó que solamente se precisaba de un acuerdo con el Ayuntamiento para que la gestión del cementerio islámico fuera permitida. El Patronato se convertía -voluntaria o involuntariamente- en una fuente alternativa de legitimidad de las comunidades frente al gobierno municipal (Soddu, 2003).

Debido a la creciente espiral de demandas, se constituyó en 1999 el Consejo Islámico de Granada (CIG). Este Consejo fue creado bajo los auspicios de las entonces cinco comunidades musulmanas y el gobierno local, que quería un negociador unitario. El CIG recibió el apoyo de la Federación Española de Entidades Religiosas Islámica (FEERI), pero no así de la Unión de Comunidades Islámicas de España (UCIDE), ambos en lucha a nivel nacional. Se esperaba que el CIG actuara de forma coordinada y unitaria en la defensa y la búsqueda del interés musulmán en Granada, mientras que se mantendría la autonomía de las comunidades. Sin embargo, su incapacidad para registrarse como entidad religiosa en el Ministerio de Justicia (por lo que no fue legalizado) re restaría representatividad.

No fue hasta el año 2006 que el CIG pudo ser legalizado, tras un período de relativa inoperancia. A pesar de los problemas que plagaron su política interna desde su creación, el CIG logró firmar en 2002 el deseado acuerdo sobre el cementerio islámico. Sus delegados, el converso Pedro Coca Domínguez (Abu Umar Muhammad) y Manuel Maza Vielva (Zakaria Al-Qurtubi), eran personas calificadas y respetadas del Islam en Granada y representantes de dos comunidades islámicas de la ciudad (respectiva- mente, la Junta Islámica y la Comunidad Islámica Española de la Mezquita de Al-Taqwa). Sin embargo, algunas comunidades fueron críticas acerca de los intereses individuales que habían guiado las negociaciones, en particular, destacando los lazos de amistad entre los "conversos" y las autoridades.

Este acuerdo legalizaba los entierros, pero no consiguió que el Ayuntamiento llevara a cabo las reformas esenciales en el cementerio. En 2008 el Ministerio de Cultura -a través del Instituto Español del Patrimonio Histórico- informó que la remodelación del cementerio comenzaría de forma inmediata asumiendo el coste de las obras. El cementerio islámico podría disponer de 577 tumbas en un área de 4500 $\mathrm{m} 2$. La gestión, control y administración de los locales recaerían en EMUCESA, una empresa pública local encargada de las obras, mientras que todo lo relacionado con los enterramientos se llevarían a cabo por personal designado por las comunidades musulmanas.

Finalmente en enero de 2009, el cementerio islámico fue inaugurado. La ceremonia de inauguración contó con la presencia, en nombre de las comunidades musulmanas, de Zakaria Maza, presidente de la Comunidad Islámica Española de la Mezquita de AlTaqwa, Abdul-Qader Abu Husni e Ibrahim López, presidente y portavoz de la Mezquita "As-Salam". En nombre de las autoridades que asistieron María del Mar Villafranca, directora del Patronato de la Alhambra, José Torres Hurtado, Alcalde de Granada, Antonio Cruz, Subdelegado del Gobierno español en Granada, y Castro Antón, Subdirector del Instituto Español del Patrimonio Histórico. Todos ellos coincidieron en la importancia de la reforma del cementerio islámico como un ejemplo de integración social de las comunidades musulmanas en Granada.

\subsection{La celebración del Día de la Toma: apo- yos ciudadanos y extremismos políticos ${ }^{12}$}

El Día de la Toma es una celebración histórica que cada 2 de enero conmemora la toma de posesión de la Alhambra por los Reyes Católicos y el fin de la Reconquista. Desde comienzos de la democracia la celebración ha generado una polémica permanente entre los partidarios de la continuidad de la tradi-

${ }^{12}$ Esta cuestión ha sido ampliamente tratada por Rosón (2008). 


\begin{tabular}{|c|c|c|c|c|c|c|}
\hline \multirow[b]{2}{*}{ Nombre } & \multirow[b]{2}{*}{ Tipología } & \multirow[b]{2}{*}{ Categoría } & \multicolumn{4}{|c|}{ Características } \\
\hline & & & Objetivos & $\begin{array}{c}\text { Rasgos } \\
\text { organizativos }\end{array}$ & Presencia & $\begin{array}{c}\text { Nivel de } \\
\text { comunicación }\end{array}$ \\
\hline $\begin{array}{l}\text { Instituto } \\
\text { Español de } \\
\text { Patrimonio } \\
\text { Histórico }\end{array}$ & $\begin{array}{l}\text { Organismo } \\
\text { público } \\
\text { (Ministerio } \\
\text { de Cultura) }\end{array}$ & Institucional & $\begin{array}{l}\text { Acceder a las deman- } \\
\text { das de los musulma- } \\
\text { nes pero preservando } \\
\text { el patrimonio }\end{array}$ & $\begin{array}{c}\text { Organismo } \\
\text { público dotado de } \\
\text { presupuesto propio }\end{array}$ & Alta & Medio \\
\hline $\begin{array}{l}\text { Subdele- } \\
\text { gación del } \\
\text { Estado en } \\
\text { Granada }\end{array}$ & $\begin{array}{l}\text { Autoridad } \\
\text { estatal }\end{array}$ & Institucional & $\begin{array}{l}\text { Reformar el cemente- } \\
\text { rio desde el consenso }\end{array}$ & $\begin{array}{c}\text { Legitimidad } \\
\text { gubernamental }\end{array}$ & Alta & Alto \\
\hline $\begin{array}{l}\text { Patronato } \\
\text { de la Al- } \\
\text { hambra y } \\
\text { del } \\
\text { Generalife } \\
\end{array}$ & $\begin{array}{l}\text { Agencia } \\
\text { pública } \\
\text { estatal - } \\
\text { regional }\end{array}$ & Institucional & $\begin{array}{l}\text { Acceder a las deman- } \\
\text { das de los musulma- } \\
\text { nes sin perjudicar el } \\
\text { patrimonio }\end{array}$ & $\begin{array}{l}\text { Organismo dotado } \\
\text { de presupuesto } \\
\text { propio. }\end{array}$ & Alta & Alto \\
\hline $\begin{array}{l}\text { Ayunta- } \\
\text { miento de } \\
\text { Granada }\end{array}$ & $\begin{array}{l}\text { Autoridad } \\
\text { municipal }\end{array}$ & Institucional & $\begin{array}{l}\text { Reformar el cemente- } \\
\text { rio sin que ello genere } \\
\text { tensión social }\end{array}$ & Autoridad local & Media & Bajo \\
\hline EMUCESA & $\begin{array}{l}\text { Empresa } \\
\text { pública } \\
\text { municipal }\end{array}$ & Institucional & $\begin{array}{l}\text { Dependen de lo } \\
\text { acordado por el } \\
\text { Ayuntamiento }\end{array}$ & Empresa & Alta & Bajo \\
\hline $\begin{array}{l}\text { Comunidad } \\
\text { Islámica en } \\
\text { España }\end{array}$ & $\begin{array}{l}\text { Comunidad } \\
\text { islámica }\end{array}$ & Comunidad & $\begin{array}{l}\text { Reformar el } \\
\text { cementerio }\end{array}$ & $\begin{array}{l}\text { Primera comuni- } \\
\text { dad islámica esta- } \\
\text { blecida en Granada }\end{array}$ & Baja & Bajo \\
\hline $\begin{array}{l}\text { Consejo } \\
\text { Islámico de } \\
\text { Granada }\end{array}$ & $\begin{array}{l}\text { Asociación } \\
\text { local }\end{array}$ & Asociación & $\begin{array}{l}\text { Coordinar a las co- } \\
\text { munidades islámicas }\end{array}$ & $\begin{array}{c}\text { Entidad religiosa } \\
\text { cuya representati- } \\
\text { vidad es intermi- } \\
\text { tente }\end{array}$ & Baja & Bajo \\
\hline $\begin{array}{c}\text { Comunidad } \\
\text { Musulmana } \\
\text { Española de } \\
\text { la Mezquita } \\
\text { del Temor } \\
\text { Allah en } \\
\text { Granada } \\
\end{array}$ & $\begin{array}{l}\text { Comunidad } \\
\text { islámica }\end{array}$ & Comunidad & $\begin{array}{l}\text { Reformar el } \\
\text { cementerio }\end{array}$ & $\begin{array}{l}\text { Segunda comu- } \\
\text { nidad islámica } \\
\text { establecida en } \\
\text { Granada, escindida } \\
\text { de la Comunidad } \\
\text { Islámica en España }\end{array}$ & Alta & Alto \\
\hline $\begin{array}{l}\text { Mezquita } \\
\text { de la Paz } \\
\text { "As-Salam" }\end{array}$ & $\begin{array}{l}\text { Comunidad } \\
\text { islámica }\end{array}$ & Comunidad & $\begin{array}{l}\text { Reformar el } \\
\text { cementerio }\end{array}$ & $\begin{array}{l}\text { Comunidad islámi- } \\
\text { ca más numerosa } \\
\text { de Granada }\end{array}$ & Baja & Bajo \\
\hline $\begin{array}{l}\text { Comunidad } \\
\text { Musulmana } \\
\text { de Granada }\end{array}$ & $\begin{array}{l}\text { Comunidad } \\
\text { islámica }\end{array}$ & Comunidad & $\begin{array}{l}\text { Reformar el } \\
\text { cementerio }\end{array}$ & $\begin{array}{c}\text { Tercera comunidad } \\
\text { islámica estableci- } \\
\text { da en Granada }\end{array}$ & Baja & Bajo \\
\hline $\begin{array}{l}\text { Asociación } \\
\text { "Masical } \\
\text { Jinan" }\end{array}$ & $\begin{array}{l}\text { Comunidad } \\
\text { islámica }\end{array}$ & Comunidad & $\begin{array}{l}\text { Reformar el } \\
\text { cementerio }\end{array}$ & $\begin{array}{l}\text { Exclusiva para } \\
\text { senegaleses }\end{array}$ & Baja & Bajo \\
\hline $\begin{array}{l}\text { Partido } \\
\text { Popular }\end{array}$ & $\begin{array}{l}\text { Partido } \\
\text { político }\end{array}$ & $\begin{array}{l}\text { Actor polí- } \\
\quad \text { tico }\end{array}$ & $\begin{array}{c}\text { Apaciguar las } \\
\text { demandas de los } \\
\text { musulmanes }\end{array}$ & $\begin{array}{l}\text { Partido de gobier- } \\
\text { no en Granada }\end{array}$ & Baja & Bajo \\
\hline PSOE & $\begin{array}{l}\text { Partido } \\
\text { político }\end{array}$ & $\begin{array}{l}\text { Actor polí- } \\
\text { tico }\end{array}$ & $\begin{array}{c}\text { Dialogar con y } \\
\text { acercarse a los } \\
\text { musulmanes }\end{array}$ & $\begin{array}{l}\text { Segunda fuerza } \\
\text { política en } \\
\text { Granada }\end{array}$ & Baja & Bajo \\
\hline
\end{tabular}


cional celebración y los que reivindican las raíces históricas de Al-Ándalus. El Día de la Toma adquirió durante la dictadura franquista un exacerbado carácter nacionalista, pero con la llegada del PSOE en 1979 al poder municipal se imprimió a la fiesta un perfil más alto para recuperar su sentido histórico general. Sin embargo, rápidamente se inició un proceso de rechazo de la festividad por parte de una minoría de intelectuales de izquierda granadinos y andaluces (por considerarla acentuadamente militarista, nacionalista y católica). En 1981 se iniciaron las primeras protestas pacíficas contra su celebración (Navarro, 1998), a las que seguirían, en 1983 y 1984, los actos culturales alternativos denominados "Llanto por Granada".

Los actos de protesta fueron retomados en la segunda mitad de los 80 por diversas comunidades islámicas y por colectivos andalucistas, ${ }^{13}$ pero fue a partir de 1992 cuando la celebración del V centenario de la Toma y el aumento en la intensidad de las reivindicaciones de los actores contrarios a ella permitieron a esta cuestión instalarse en un lugar prioritario de la agenda política municipal, especialmente propiciado por la insistencia del Partido Andalucista (PA). Las comunidades y el resto de formaciones sociales islámicas granadinas habían declarado que evitarían aquel día su presencia en las calles más céntricas y concurridas de Granada, pero los colectivos Identidad Andaluza (IA) y Nación Andaluza (NA) acabarían celebrando el mencionado acto. Estos grupos fueron sorprendidos por una contra-protesta ultraderechista (Navarro 1998: 32), que increpó a las autoridades y pretendió convertir el $\mathrm{V}$ centenario de la Toma en una celebración de exaltación nacionalista española. En aquel momento ya se estaban gestando en el seno de la sociedad civil granadina los primeros grupos de interés defensores de la celebración del Día de la Toma. Sin embargo, aquellos incidentes no propiciaron ningún cambio significativo en la celebración.

Entre 1993 y 1995 se sucedieron las protestas lideradas por los mismos grupos. Por entonces existía una comunión de intereses y una estrategia compartida entre sectores independentistas del PA y las comunidades islámicas, que por entonces eran tres: la Comunidad Islámica en España, la Comunidad Musulmana Española de la Mezquita del Temor Allah en Granada y la Comunidad Musulmana de Granada.. Ello era reflejo de bases ideológicas comunes, que compartían el sentimiento nacionalista andaluz y el pilar islámico sobre el cual éste debía sustentarse. No obstante, los dirigentes de las comunidades consideraban que su participación directa y visible en los actos de boicot no violento de la celebración podía acarrearles más perjuicios que beneficios, fundamentalmente por su exposición mediática; $;{ }^{14} \mathrm{de}$ ahí que Nación Andaluza acaparase todo el protagonismo.

Para intentar imprimir otro tono a las protestas, en 1995 se publicó el "Manifiesto 2 de Enero", firmado por un centenar de escritores, artistas, académicos, etc., promovido por el Colectivo Manifiesto 2 de Enero, que había comenzado a gestarse en 1994. Los firmantes propusieron convertir la celebración en una jornada de reconciliación entre las culturas cristiana, musulmana y judía. Estos objetivos eran compartidos también por la Asamblea Civil, un grupo emergente integrado por los intelectuales que celebraron el primer "Llanto por Granada" y que ahora optaban por realizar actos de concienciación de la sociedad civil. En 1995 miembros de la Asamblea Civil y promotores del Manifiesto 2 de Enero comenzaron a mostrarse muy activos en sus reivindicaciones sobre el Día de la Toma, y durante 19961997 coordinaron sus acciones de rechazo.

Precisamente en el bienio 1996-1997 sucedieron tres importantes acontecimientos: a) el periódico

\footnotetext{
${ }^{13}$ Entre ellos destacaron: a) la coordinadora Identidad Andaluza (IA), cuyo discurso nacionalista-regionalista se centraba exclusivamente sobre las señas identitarias del Islam, en el que el Partido Andalucista y sus Juventudes desempeñaron un papel crucial; b) la "Yama'a Islámica de Al-Andalus" (Liga Morisca), un grupo municipal de interés religioso islámico; y c) Nación Andaluza (NA), la más beligerante. A ellos se sumaría, a partir de 1991, d) el Comité "Andalucía-Nación", de perfil independentista, por considerar que la celebración reflejaba el pasado imperialista y colonizador castellano..

${ }^{14}$ En 1994 y 1995 se registraron pequeños incidentes que fueron recogidos por la prensa tanto local como estatal, que hicieron especial mención de la coincidencia de intereses entre grupos nacionalistas y comunidades islámicas.
} 
Ideal publicó un sondeo de opinión sobre la celebración, que situó en casi el $85 \%$ el porcentaje de granadinos partidarios de ella; b) el Gobierno municipal del PP -en el poder desde 1995- inauguró una estatua en memoria de Boabdil ${ }^{15}$ para integrar su homenaje en ulteriores ediciones del Día de la Toma; y c) tuvo lugar la primera declaración explícita pública respecto al Día de la Toma por parte de una comunidad islámica de Granada, concretamente la Comunidad Islámica en España. Ésta, adoptando una postura intermedia en el conflicto, felicitó públicamente al Gobierno municipal por los cambios; felicitación que para muchos no era más que un intento para mejorar su imagen ante las críticas que venía acumulando. Fuese o no consecuencia de la presión ejercida sobre los decisores políticos municipales, en 1997 el Gobierno municipal del PP llevó a cabo la primera modificación de la celebración después de casi dos décadas. Para entonces, otro sector se había organizado definitivamente en defensa de la continuidad de la celebración en torno a grupos de interés entre los que destacaba la Asociación Granada Histórica y Cultural.

Durante las fechas previas al 2 de enero de 1998 arreció la polémica, con la participación activa de otro grupo de reciente creación: la asociación Granada Tradicional, que exigió respetar la celebración por considerar que conmemoraba fielmente hechos históricos, y se mostró parcialmente en contra de las modificaciones introducidas. El Colectivo Manifiesto 2 de Enero volvió a demandar la conversión de la celebración en una fiesta por la tolerancia, y NA criticó nuevamente una festividad que a su entender conmemoraba un genocidio. Además, las comunidades islámicas -cada vez más visiblemente activas públicamente al respecto-, señalaron que el homenaje a Boabdil era contrario a la costumbre musulmana de no venerar la iconografía humana. La mayor parte de los actores de la red involucrados, como forma de rechazo, se ausentó el 2 de enero de 1998 del recién incorporado homenaje.

A partir de 1999, año electoral, la celebración se situó como tema prioritario en la agenda política municipal. PSOE, IU y PA incluyeron en sus pro- gramas electorales la modificación de la celebración, mientras que el PP defendió la continuidad y mantenimiento de la misma. La polémica alcanzó su punto álgido cuando, tras formar el PSOE, IU y el PA un gobierno municipal de coalición, IU hizo suyas todas las propuestas del Colectivo Manifiesto 2 de Enero. Con tal fin, por iniciativa del nuevo Gobierno, se constituyó una comisión -que incluía a representantes de algunas comunidades islámicas- que acordó suprimir la ofrenda a Boabdil, celebrar un concierto de música arábigo-andalusí; introducir la lectura de un comunicado en favor de la convivencia y la tolerancia; y reducir la presencia militar. Dichas modificaciones suscitaron las protestas del PP, de los grupos de interés defensores del mantenimiento de la tradicional celebración y de grupúsculos de ultra derecha. Aquel contexto fue aprovechado por las comunidades islámicas para, a través del CIG, desvincularse de la postura pública mantenida dos años atrás (1997) por la Comunidad Islámica en España. El CIG manifestó públicamente en enero de 2000 su acuerdo con las modificaciones adoptadas por el nuevo Gobierno municipal, que fueron canalizadas institucionalmente a través de la participación de todas las partes en el recién creado Foro de las Culturas, y consideró positiva cualquier modificación, por mínima que fuese.

La celebración pasó a denominarse "Fiesta de Granada", mantuvo las modificaciones del año anterior e introdujo otras. Sin embargo, grupos contrarios a la modificación ${ }^{16}$ se mostraron desde 2001 particularmente activos optando por una estrategia de deslegitimación de los partidarios de las modificaciones y del propio Foro. Surgió así el movimiento ciudadano "Y Granada, ¿Qué?", a través del cual Granada Histórica y Cultural intentó coordinar los esfuerzos de los actores partidarios de la celebración. Estas iniciativas dieron su fruto y la celebración fue nuevamente modificada: el 2 de enero de 2002 se suprimió la lectura del "manifiesto por la tolerancia" y se recuperó la presencia de una numerosa escolta militar. Desde 2002 hasta 2008 el protocolo de la celebración del Día de la Toma permaneció inalterado, pero la polémica se mantuvo a causa

\footnotetext{
${ }^{15}$ Baobdil fue el último rey nazarí de Granada.

${ }^{14}$ Nos referimos especialmente a Granada Histórica y Cultural, Granada Tradicional, Mujeres por Granada y la Plataforma Pro 2 de enero.
} 
de la presencia activa en la celebración de actores de ultra derecha, particularmente los partidos Democracia Nacional, España 2000 y FE de las JONS. Por su parte, las comunidades islámicas y el resto de actores partidarios de la modificación o supresión de la celebración, continuaron haciendo hincapié en el ejemplo a repetir de la supuesta convivencia pretérita entre musulmanes, cristianos y judíos. Desde entonces, continuaron los actos alternativos a la celebración oficial, muchos organizados por nuevos actores, pero fueron las comunidades islámicas las más activas y contundentes al respecto. Particularmente destacable fue la iniciativa de 2004, cuando la Comunidad Islámica en España celebró el "Día de la Reconciliación". Ese año, además, se conmemoró el V Centenario de la Muerte de Isabel la Católica, figura que para las comunidades islámicas y actores como NA era de la una genocida e imperialista. El Día de la Toma incorporó, por tanto, un nuevo elemento objeto de confrontación.

\begin{tabular}{|c|c|c|c|c|c|c|}
\hline \multirow[b]{2}{*}{ Nombre } & \multirow[b]{2}{*}{ Tipología } & \multirow[b]{2}{*}{ Categoría } & \multicolumn{4}{|c|}{ Características } \\
\hline & & & Objetivos & $\begin{array}{c}\text { Rasgos } \\
\text { organizativos }\end{array}$ & Presencia & $\begin{array}{l}\text { Nivel de } \\
\text { comunica- } \\
\text { ción }\end{array}$ \\
\hline PSOE & $\begin{array}{l}\text { Partido } \\
\text { político }\end{array}$ & Actor político & $\begin{array}{l}\text { Atender parcialmente } \\
\text { las demandas de los } \\
\text { actores contrarios a la } \\
\text { celebración }\end{array}$ & $\begin{array}{l}\text { Segunda fuerza polí- } \\
\text { tica en Granada }\end{array}$ & Media & Medio \\
\hline $\begin{array}{l}\text { Colectivo Manifies- } \\
\text { to } 2 \text { de enero }\end{array}$ & $\begin{array}{l}\text { Asociación } \\
\text { local }\end{array}$ & Asociación & $\begin{array}{l}\text { Modificación o supre- } \\
\text { sión de la celebración }\end{array}$ & $\begin{array}{l}\text { Intelectuales de } \\
\text { izquierda }\end{array}$ & Alta & Alto \\
\hline Identidad Andaluza & $\begin{array}{l}\text { Asociación } \\
\text { local }\end{array}$ & Asociación & $\begin{array}{l}\text { Modificación o supre- } \\
\text { sión de la celebración }\end{array}$ & $\begin{array}{l}\text { Protesta activa con- } \\
\text { tra la celebración }\end{array}$ & Alta & Alto \\
\hline $\begin{array}{l}\text { Partido Andalucista } \\
\text { y sus Juventudes }\end{array}$ & $\begin{array}{l}\text { Partido } \\
\text { político }\end{array}$ & Actor político & $\begin{array}{l}\text { Modificación o supre- } \\
\text { sión de la celebración }\end{array}$ & $\begin{array}{c}\text { Fuerza política } \\
\text { con representación } \\
\text { intermitente en el } \\
\text { Ayuntamiento de } \\
\text { Granada }\end{array}$ & Media & Medio \\
\hline $\begin{array}{c}\text { Yama'a Islámica de } \\
\text { Al-Andalus (Liga } \\
\text { Morisca) }\end{array}$ & $\begin{array}{l}\text { Asociación } \\
\text { local }\end{array}$ & Asociación & $\begin{array}{l}\text { Modificación o supre- } \\
\text { sión de la celebración }\end{array}$ & $\begin{array}{l}\text { Organización cultu- } \\
\text { ral de musulmanes } \\
\text { andaluces escindida } \\
\text { del Frente de Libera- } \\
\text { ción de Andalucía }\end{array}$ & Alta & Alto \\
\hline Nación Andaluza & $\begin{array}{l}\text { Partido } \\
\text { político }\end{array}$ & Actor político & $\begin{array}{l}\text { Modificación o supre- } \\
\text { sión de la celebración }\end{array}$ & $\begin{array}{c}\text { Fuerza política sin } \\
\text { representación }\end{array}$ & Alta & Alto \\
\hline $\begin{array}{l}\text { Comité Andalucía- } \\
\text { Nación }\end{array}$ & $\begin{array}{c}\text { Asociación } \\
\text { local }\end{array}$ & Asociación & $\begin{array}{l}\text { Modificación o supre- } \\
\text { sión de la celebración }\end{array}$ & $\begin{array}{l}\text { Protesta activa con- } \\
\text { tra la celebración }\end{array}$ & Alta & Alto \\
\hline $\begin{array}{l}\text { Comunidad Mu- } \\
\text { sulmana de Al- } \\
\text { Andalus }\end{array}$ & $\begin{array}{l}\text { Comunidad } \\
\text { islámica }\end{array}$ & Comunidad & $\begin{array}{l}\text { Modificación o supre- } \\
\text { sión de la celebración }\end{array}$ & $\begin{array}{c}\text { Comunidad islámica } \\
\text { disuelta a comienzos } \\
\text { de los } 80\end{array}$ & Alta & Medio \\
\hline $\begin{array}{l}\text { Comunidad Islámi- } \\
\text { ca en España }\end{array}$ & $\begin{array}{l}\text { Comunidad } \\
\text { islámica }\end{array}$ & Comunidad & $\begin{array}{l}\text { Modificación o supre- } \\
\text { sión de la celebración }\end{array}$ & $\begin{array}{c}\text { Primera comunidad } \\
\text { islámica establecida } \\
\text { en Granada }\end{array}$ & Alta & Medio \\
\hline $\begin{array}{c}\text { Comunidad Mu- } \\
\text { sulmana Española } \\
\text { de la Mezquita del } \\
\text { Temor Allah en } \\
\text { Granada }\end{array}$ & $\begin{array}{l}\text { Comunidad } \\
\text { islámica }\end{array}$ & Comunidad & $\begin{array}{l}\text { Modificación o supre- } \\
\text { sión de la celebración }\end{array}$ & $\begin{array}{l}\text { Segunda comunidad } \\
\text { islámica establecida } \\
\text { Granada, escindida } \\
\text { de la Comunidad } \\
\text { Islámica en España }\end{array}$ & Alta & Alto \\
\hline $\begin{array}{l}\text { Comunidad Musul- } \\
\text { mana de Granada }\end{array}$ & $\begin{array}{l}\text { Comunidad } \\
\text { islámica }\end{array}$ & Comunidad & $\begin{array}{l}\text { Modificación o supre- } \\
\text { sión de la celebración }\end{array}$ & $\begin{array}{c}\text { Tercera comunidad } \\
\text { islámica establecida } \\
\text { en Granada }\end{array}$ & Alta & Alto \\
\hline Asamblea Civil & $\begin{array}{l}\text { Asociación } \\
\text { local }\end{array}$ & Asociación & $\begin{array}{l}\text { Modificación o supre- } \\
\text { sión de la celebración }\end{array}$ & $\begin{array}{l}\text { Protesta activa con- } \\
\text { tra la celebración }\end{array}$ & Alta & Alto \\
\hline
\end{tabular}




\begin{tabular}{|c|c|c|c|c|c|c|}
\hline \multirow[b]{2}{*}{ Nombre } & \multirow[b]{2}{*}{ Tipología } & \multirow[b]{2}{*}{ Categoría } & \multicolumn{4}{|c|}{ Características } \\
\hline & & & Objetivos & $\begin{array}{c}\text { Rasgos } \\
\text { organizativos }\end{array}$ & Presencia & $\begin{array}{l}\text { Nivel de } \\
\text { comunica- } \\
\text { ción }\end{array}$ \\
\hline Izquierda Unida & $\begin{array}{l}\text { Partido } \\
\text { político }\end{array}$ & Actor político & $\begin{array}{l}\text { Modificación o supre- } \\
\text { sión de la celebración }\end{array}$ & $\begin{array}{l}\text { Tercera fuerza políti- } \\
\text { ca en Granada }\end{array}$ & Media & Medio \\
\hline $\begin{array}{l}\text { Consejo Islámico } \\
\text { de Granada }\end{array}$ & $\begin{array}{l}\text { Asociación } \\
\text { local }\end{array}$ & Asociación & $\begin{array}{l}\text { Modificación o supre- } \\
\text { sión de la celebración }\end{array}$ & $\begin{array}{l}\text { Entidad religiosa } \\
\text { cuya representativi- } \\
\text { dad es intermitente }\end{array}$ & Alta & Alto \\
\hline Iglesia Católica & $\begin{array}{l}\text { Confesión } \\
\text { religiosa }\end{array}$ & Religiosa & $\begin{array}{l}\text { Mantenimiento de la } \\
\text { celebración o realizar } \\
\text { modificaciones muy li- } \\
\text { mitadas y superficiales }\end{array}$ & Religión mayoritaria & Baja & Bajo \\
\hline FE de las JONS & $\begin{array}{l}\text { Partido } \\
\text { político }\end{array}$ & Actor político & $\begin{array}{l}\text { Mantenimiento de la } \\
\text { celebración o realizar } \\
\text { modificaciones muy li- } \\
\text { mitadas y superficiales }\end{array}$ & $\begin{array}{l}\text { Fuerza política sin } \\
\text { representación }\end{array}$ & Alta & Alto \\
\hline $\begin{array}{l}\text { Democracia } \mathrm{Na}- \\
\text { cional }\end{array}$ & $\begin{array}{l}\text { Partido } \\
\text { político }\end{array}$ & Actor político & $\begin{array}{l}\text { Mantenimiento de la } \\
\text { celebración o realizar } \\
\text { modificaciones muy li- } \\
\text { mitadas y superficiales }\end{array}$ & $\begin{array}{l}\text { Fuerza política sin } \\
\text { representación }\end{array}$ & Alta & Alto \\
\hline $\begin{array}{l}\text { Foro de las Cul- } \\
\text { turas }\end{array}$ & $\begin{array}{l}\text { Órgano } \\
\text { consultivo } \\
\text { municipal }\end{array}$ & Institucional & $\begin{array}{c}\text { Consensuar una deci- } \\
\text { sión sobre la celebra- } \\
\text { ción para resolver la } \\
\text { polémica }\end{array}$ & $\begin{array}{l}\text { Legitimidad guber- } \\
\text { namental }\end{array}$ & Media & Medio \\
\hline $\begin{array}{l}\text { Mujeres por Gra- } \\
\text { nada }\end{array}$ & $\begin{array}{l}\text { Asociación } \\
\text { local }\end{array}$ & Asociación & $\begin{array}{l}\text { Mantenimiento de la } \\
\text { celebración o realizar } \\
\text { modificaciones muy li- } \\
\text { mitadas y superficiales }\end{array}$ & $\begin{array}{l}\text { Asociación integran- } \\
\text { te del Foro de las } \\
\text { Culturas }\end{array}$ & Media & Medio \\
\hline $\begin{array}{c}\text { Plataforma Pro } 2 \\
\text { de enero }\end{array}$ & $\begin{array}{l}\text { Asociación } \\
\text { local }\end{array}$ & Asociación & $\begin{array}{l}\text { Mantenimiento de la } \\
\text { celebración o realizar } \\
\text { modificaciones muy li- } \\
\text { mitadas y superficiales }\end{array}$ & $\begin{array}{l}\text { Asociación integran- } \\
\text { te del Foro de las } \\
\text { Culturas }\end{array}$ & Alta & Alto \\
\hline $\begin{array}{l}\text { "Y Granada } \\
\text { ¿Qué?" }\end{array}$ & $\begin{array}{l}\text { Asociación } \\
\text { local }\end{array}$ & Asociación & $\begin{array}{l}\text { Mantenimiento de la } \\
\text { celebración o realizar } \\
\text { modificaciones muy li- } \\
\text { mitadas y superficiales }\end{array}$ & $\begin{array}{l}\text { Coordinador de las } \\
\text { asociaciones defen- } \\
\text { soras de la celebra- } \\
\text { ción }\end{array}$ & Alta & Alto \\
\hline $\begin{array}{l}\text { Democracia Na- } \\
\text { cional }\end{array}$ & $\begin{array}{l}\text { Partido } \\
\text { político }\end{array}$ & Actor político & $\begin{array}{l}\text { Mantenimiento de la } \\
\text { celebración o realizar } \\
\text { modificaciones muy li- } \\
\text { mitadas y superficiales }\end{array}$ & $\begin{array}{l}\text { Fuerza política sin } \\
\text { representación }\end{array}$ & Alta & Alto \\
\hline España 2000 & $\begin{array}{l}\text { Partido } \\
\text { político }\end{array}$ & Actor político & $\begin{array}{l}\text { Mantenimiento de la } \\
\text { celebración o realizar } \\
\text { modificaciones muy li- } \\
\text { mitadas y superficiales }\end{array}$ & $\begin{array}{l}\text { Fuerza política sin } \\
\text { representación }\end{array}$ & Alta & Alto \\
\hline $\begin{array}{l}\text { Asociación "Masa- } \\
\text { lical Jinan" }\end{array}$ & $\begin{array}{l}\text { Comunidad } \\
\text { islámica }\end{array}$ & Comunidad & $\begin{array}{l}\text { Modificación o supre- } \\
\text { sión de la celebración }\end{array}$ & $\begin{array}{c}\text { Exclusiva para } \\
\text { senegaleses }\end{array}$ & Alta & Alto \\
\hline $\begin{array}{l}\text { Mezquita de la Paz } \\
\text { "As-Salam" }\end{array}$ & $\begin{array}{l}\text { Comunidad } \\
\text { islámica }\end{array}$ & Comunidad & $\begin{array}{l}\text { Modificación o supre- } \\
\text { sión de la celebración }\end{array}$ & $\begin{array}{c}\text { Comunidad islámica } \\
\text { más numerosa de } \\
\text { Granada }\end{array}$ & Alta & Alto \\
\hline
\end{tabular}

Fuente: Elaboración propia. 


\section{APUNTES FINALES SOBRE LAS CARACTERÍSTICAS Y DINÁMICAS ENTRE LOS ACTORES}

La política del cementerio islámico de Granada ha puesto de manifiesto las dificultades de entendimiento entre las propias comunidades musulmanas locales. También se ha destacado la complicada relación entre los musulmanes con las autoridades locales. La actitud del gobierno municipal se ha caracterizado por la constante negación y el olvido de los compromisos. Más de treinta años han sido necesarios para lograr entierros musulmanes en las condiciones reivindicadas. No todas las comunidades optaron por participar de forma activa en la defensa de un bien que a todas ellas, tarde o temprano, acabaría afectando. Resulta curioso cuanto menos que un tema central para una confesión religiosa, como es el lugar de descanso de sus difuntos, no sea un tema que movilice a todas por igual. Puede ser que esta falta de presencia colectiva haya sido la base para que los actores locales (Ayuntamiento y EMUCESA), al no ver una respuesta contundente a su inacción, no hayan tenido un liderazgo decisivo a lo largo de estas últimas décadas ni mucho menos hayan construido puentes de diálogo con las comunidades.

La falta de acuerdos formales a lo largo de todo el proceso da muestras del carácter outsider de las comunidades y, a consecuencia de ello, sus tácticas de influencia han carecido de formalismo. No obstante, la perseverancia en la política que han demostrado y la claridad de sus objetivos (que no han cambio con el tiempo) parece ser su mayor recurso para plantear una estrategia de presión a largo tiempo en la que se buscaba la confidencia de otro tipo de actores, al margen de las autoridades locales, que les diera legitimidad en sus demandas. Este punto es interesante para resaltar que las dinámicas multinivel han sido importantes para lograr finalmente disponer del cementerio islámico. Todo hace pensar que si hubiera sido una negociación exclusiva a nivel local, ante la parsimonia mostrada por el Ayuntamiento, a día de hoy dicho cementerio no sería una realidad.

Por lo general, los contactos no han sido fluidos, la presencia de los actores ha sido intermitente mientras que las tensiones han sido permanentes. Si ha habido una cosa clara durante todo el proceso es que las autoridades locales han sido capaces de aplacar las demandas de las comunidades musulmanas durante un largo periodo de tiempo. En otros casos, los acuerdos han fracasado debido a la incapacidad de las comunidades de crear un interlocutor representativo, único y común. Debido a ello, las comunidades no han tenido otra opción que aceptar el liderazgo de miembros individuales, un liderazgo definido por la relación de amistad con el responsable político de tomar la decisión sobre el asunto.

Por otro lado, esta falta de liderazgo caracteriza también la participación de las comunidades islámicas de Granada en las posiciones contrarias a la celebración de la Toma. Hasta la segunda mitad de los 90 no se manifestaron pública y visiblemente en contra de ella, sino que optaron por estrategias como la colaboración con actores ideológicamente afines, fundamentalmente con representantes del nacionalismo andaluz, que llevaban el peso de las protestas. No fue hasta que hubo una alternancia en el gobierno municipal a finales de los 90, aparentemente más cercanos a sus propuestas, que el CIG emitió las primeras manifestaciones públicas -claras y contundentes- ante los medios de comunicación en contra de la celebración. Eso demuestra que durante años las comunidades consideraban mínima su capacidad de influencia sobre la toma de decisiones del gobierno municipal.

No obstante, la creación del Foro de las Culturas tampoco aseguró el éxito de los intereses de las comunidades. Esta institucionalización de las negociaciones debe ser interpretada preferentemente como un intento por parte del gobierno municipal tripartido de hacer suya tanto la propia polémica como su resolución con el fin de legitimarse ante el electorado granadino. Debido a la incapacidad gubernamental y a la tensión política, en ningún caso las comunidades islámicas consiguieron que la celebración se modificase definitivamente ni mucho menos que se suprimiera. Las modificaciones obedecieron esencialmente a decisiones personales coyunturales adoptadas por miembros individuales de los gobiernos municipales sobre la base de alteraciones sobrevenidas de la agenda municipal.

De nuevo, cabe resaltar que, anteriormente a la unidad de discurso mediante el CIG, las comunidades islámicas adoptaban posiciones egocéntricas basadas en sus intereses particulares sin tener el cuenta la visión del resto. Empero, la unidad de discurso no ha resultado ser más efectiva en vista de los resul- 
tados, aunque sí ha conseguido dotar a los musulmanes de una personalidad definida y un mensaje propio diferenciado del resto de actores que durante años desvirtuaron sus objetivos. Desde entonces, la postura reivindicativa de las comunidades fue creciendo en intensidad, con puntos particularmente álgidos, como el 2002 a raíz de la supresión por parte del Gobierno municipal de las modificaciones introducidas en 2000 y 2001.

Por último, de los principales sucesos expuestos anteriormente se desprende, en comparación con el primer estudio de caso, que la celebración del Día de la Toma ha generado un mayor rechazo ciudadano al pretenderse modificar o suprimir (desde las posi- ciones musulmanas) un elemento cultural referente del catolicismo. Es relevante la postura adoptada por la Iglesia a favor de una celebración tradicionalista acorde con su imaginario. A pesar de la aparición de grupos defensores de posiciones de concordia, la proliferación de grupos extremistas ha ido in crescendo, por lo que ha sido complicado que se pudiera dar una solución moderada y pactada entre todas las partes. Las comunidades islámicas, más visibles y cohesionadas en la última fase del proceso que en décadas previas, no han podido más que alzar la voz, reafirmar su postura u organizar actividades alternativas ante las amenazas violentas de los partidarios de la celebración.

\section{BIBLIOGRAFÍA}

Bachrach, P. y M. S. Baratz (1962) “Two faces of power” The American Political Science Review 56(4): 947-952.

BaIL, C. A. (2008) "The Configuration of Symbolic Boundaries against Immigrants in Europe" American Sociological Review 73: 37-59

Baumgartner, F. R. y B. Leech (1998): Basic Interests: The Importance of groups in Politics and in Political Science, Princeton, Princeton University Press.

Bentley, A. F. (1908): The Process of Government, Chicago, University of Chicago Press.

Berry, J. M. (1977): Lobbying for the People, Princeton, Princeton University Press.

BuAdes, J. y F. Vidal (2007): Minorías de lo mayor: minorías religiosas en la Comunidad Valenciana, Barcelona, Icaria Editorial.

Cerny, P. G. (2006) "Plurality, Pluralism and Power: Elements of Pluralist Analysis in an Age of Globalization", en Eisfeld, R. (ed.), Pluralism: Development in the Theory and Practice of Democracy, Opladen \& Farmington Hills, Barbara Budrich Publishers.

Chamberlin, J. R. (1974) "Provision of Collective Goods as a Function of Group Size" American Political Science Review 48: 707-716.

DAHL, R. (1957) "The Concept of Power" American Behavioural Scientist 2: 201-15.

Digesser, P. (1992) “The Fourth Face of Power" Journal of Politics 54(4): 977-1007.

Dunleavy, P. y B. O'Leary (1987): Theories of the State. The Politics of Liberal Democracy, London, MacMillan Education Ltd.

GoldBerg, D. T. (2006) "Racial Europeanization" Ethnic and Racial Studies 29: 331-364.

Grant, W. (1989): Pressure Groups, Politics and Democracy in Britain, London, Philip Allan.

Gregorian, V. (2003): Islam: a mosaic, not a monolith, Washington, DC, Brookings Institution Press.

Heinz, J., E.O. Laumann, R.H. Salisbury y R.L. Nelson (1990) "Inner Circles or Hollow Cores? Elite Networks in National Policy Systems" Journal of Politics 52: 356-390.

Kackett, R. I. J. (2005) "Rethinking the Role of Religion in the Public Sphere: Local and Global Perspectives", en Ostien, P., J.M. Nasir y F. Kogelmann (eds.), Comparative Perspectives on Shari 'ah in Nigeria, Ibadan, Spectrum Books.

Klausen, J. (2005): The Islamic Challenge: Politics and Religion in Western Europe, Oxford, Oxford University Press.

KnoKe, D. (1986) “Associations and Interest Groups" Annual Review of Sociology 12: 1-21.

Knoke, D. (1990): Political Networks. The Structural Perspective, Cambridge, Cambridge University Press. 
KNOKe, D. (1994): "Networks of Elite Structure and Decision Making”, en Wasserman, S. y J. Galaskiewicz (eds.), Advances in Social Network Analysis. Research in the Social and Behavioral Sciences, Thousand Oaks, Sage Publications.

LABRADOR, J. (2004) "Intervención social e inmigración" Portularia 4: 7-17

Linz, J. (1987) "Un siglo de política e intereses en España”, en Giner, S. y M. PÉrez Yruela (eds.), El corporatismo en España, Barcelona, Ariel.

Lukes, S. (1974): Power: A Radical View, London, Macmillan Press.

Maloney, W., G. Jordan y A. McLaughlin (1994) "Interest groups and Public Policy; the insider outsider model revisited" Journal of Public Policy 14(1): 17-36.

MarczewsKa-Rytko, M. (2003) "Religious Communities as Interest Groups", paper presentado en la CESNUR 2003 Conference, Vilnius, 9-12 abril, Lituania.

Maussen, M. (2006) "Representing and regulating Islam in France and in the Netherlands", paper presentado en el Workshop Muslims in Europe and the United States. Transatlantic comparison, Harvard University, 15-16 diciembre, Estados Unidos.

Mella, M. (1989) "Los grupos de presión en la transición política", en Tezanos, J.F., R. Cotarelo y A. DE Blas (eds.), La transición democrática española, Madrid, Sistema.

Molins, J.y A. Casademunt (2001) "Los grupos de interés", en Alcántara, M. y A. Martínez (eds.), Política y gobierno en España, Valencia, Tirant Lo Blanc.

Moreras, J. (1999): Musulmanes en Barcelona. Espacios y dinámicas comunitarias, Barcelona, CIDOB.

Navarro, T. (1998): La Mezquita de Babel. El nazismo sufista desde el Reino Unido a la Comunidad Autónoma de Andalucía, Granada, Virtual.

Peña-Ramos, J. A. (2009) "Hacia la articulación política del Islam en España. Una primera aproximación a Renacimiento y Unión" Gazeta de Antropología, 25(25) (en línea).

Peña-Ramos, J. A. e I. Medina (2011) "Interpreting Muslim Religious Interest Groups in Spain: frames, organisation, and influence" US-China Public Administration, 8(4): 387-400

Peña-Ramos, J. A. (2012): ¿'Anonymous'Islam en España?: Influencia de las comunidades islámicas como grupos de interés en las políticas públicas, España, Editorial Académica Española.

Pérez-Agote, A. (2007) "El proceso de secularización en la sociedad española" Revista CIDOB d'Afers Internacionals 77: 65-82.

Pfaff, S. y A. J. GiLl (2006) "Will a Million Muslims March? Muslim Interest Organizations and Political Integration in Europe" Comparative Political Studies 39(7): 803-828.

Rath, J., R. Penninx, K. GroenendiJK y A. Meyer (2001): Western Europe and Its Islam, Boston, Brill.

Rodríguez Ramos, A. M. (2009): Manual del Módulo III "Marco jurídico del Islam en España”, Curso de Experto en "Cultura y religión islámicas", Universidad Camilo José Cela-Universidad Nacional de Educación a Distancia (UNED), [v.15.01.09].

Rosón, F. J. (2008): ¿El retorno de Tariq? Comunidades etnorreligiosas en el Albayzín granadino [Tesis Doctoral, dir.: Dr. Gunther Dietz], Granada, Universidad de Granada, Departamento de Antropología Social.

Ruiz, E. (2003) "Spanish immigration policies: a critical approach from a human rights perspective", en Turton, D. y J. González, Bilbao (eds.), Immigration in Europe. Issues, Policies and Case Studies, Universidad de Deusto.

Salisbury, R. (1984) "Interest Representation: The Dominance of Institutions" American Political Science Review 81: 64-76.

Salisbury, R. H. (1969) “An Exchange Theory of Interest Groups" Midwest Journal of Political Science 13: $1-32$.

SchneIder, V. (2006) "Business in Policy Networks: Estimating the Relative Importance of Coporate Direct Lobbying and Representation by Trade Unions", en Coen, D. y W. Grant (eds.), Business and Government: Methods and Practice, Opladen \& Farmington Hills, Barbara Budrich Publishers.

Soddu, P. (2003) "Estudio Jurídico del Acuerdo de octubre de 2002 entre el Ayuntamiento de Granada y el Consejo Islámico de la Ciudad de Granada" Al-Qurtubi (en línea).

Stenger, K.E. (2005) "Defining Right and Wrong: Religious Interest Groups and the Creation and promotion of Morality-Based Arguments in Policy Debates", paper presentado en el Annual meeting of the Midwest Political Science Association, Chicago, 8-11 abril, Estados Unidos. 
TARrés, S. (2005): Inmigrantes extranjeros asentados en Andalucía. La religión como estrategia de adaptación de una comunidad magrebi en Sevilla [Tesis Doctoral, dir.: Dr. Salvador Rodríguez Becerra], Sevilla, Universidad de Sevilla, Departamento de Antropología.

TAYLOR, C. (2007): A Secular Age, Cambridge, Belknap Press.

Truman, D. B. (1951): The Governmental Process: Political Interests and Public Opinion, New Cork, Alfred A. Knopf.

Udenn, L. (1993) "Twenty-five Years with The Logic of Collective Action” Acta Sociologica 36(3): 239261.

Warner, C. M. y M. W. Wenner (2006) "Religion and the Political Organization of Muslims in Europe" Perspectives on Politics 4(3): 457-479.

ZaPATA-BARRero, R. (2003) "Políticas de acomodación de la inmigración y administración local: la gestión de la coexistencia", en Gullot, J. y T. Salvadó (eds.), Immigració i poders locals. Ciutats i persones, Barcelona, ICPS.

Zapata-BARrero, R. (2006) "The Muslim community and Spanish tradition. Maurophobia as a fact, and impartiality as a desideratum", en Modood, T., A. Traindafyllidou y R. Zapata-Barrero (eds.) Multiculturalism, Muslims and Citizenship. A European approach, London and New York, Routledge.

Zapata-Barrero, R. (2010) "Managing Diversity in Spanish Society: A Practical Approach" Journal of Intercultural Studies 31(4): 383-402. 